\title{
Finger-length ratios show evidence of prenatal hormone-transfer between opposite-sex twins
}

\author{
Sari M. van Anders ${ }^{\mathrm{a}, *}$, Philip A. Vernon ${ }^{\mathrm{b}}$, Christopher J. Wilbur ${ }^{\mathrm{b}}$ \\ ${ }^{a}$ Department of Psychology, Simon Fraser University, RCB 5246, 8888 University Drive, Burnaby BC, Canada V5A $1 S 6$ \\ ${ }^{\mathrm{b}}$ Department of Psychology, The University of Western Ontario, London ON, Canada
}

Received 7 June 2005; revised 8 August 2005; accepted 9 August 2005

Available online 6 September 2005

\begin{abstract}
Finger-length ratio (second to fourth finger; 2D:4D) has been associated with various measures thought to be related to prenatal androgens. In addition, hormone-transfer theory posits that hormones can transfer between twins. We examined 2D:4D in same-sex (SS) and opposite-sex (OS) dizygotic twins to test both propositions. Results show that 2D:4D is masculinized in OS females compared to SS females. This provides strong evidence that 2D:4D is laid down prenatally, and that hormones (likely androgens) can transfer from male to female fetuses. Implications for developmental timeframes for both hormone-transfer and 2D:4D are discussed.
\end{abstract}

(C) 2005 Elsevier Inc. All rights reserved.

Keywords: 2D:4D; Digit ratios; Dizygotic twins; Sex; Gender; Androgens; Fetal development; Opposite-sex twins

\section{Introduction}

Prenatal androgen exposure in animals directly affects masculinization of genitals (Nelson, 2000) and brain structures (Breedlove, 1994). Exposure to male-typical androgen levels in utero leads to more male-typical behavior, including, for example, rough-and-tumble play (Goy and Phoenix, 1972). In humans, androgen levels are far higher in male than female fetuses (Nagamani et al., 1979), and masculinization from in utero hormone exposure has been studied. Humans display considerable overlap by sex in all behavioral and many somatic variables, so 'maletypical' or 'female-typical' most often refers to only slight differences. As prenatal androgen manipulation is precluded from methodological approaches in human research, a variety of other research techniques have been employed (see Cohen-Bendahan et al., 2005b for a review).

One approach focuses on purported markers or sequelae of prenatal hormone exposure, in hopes of using these as

\footnotetext{
* Corresponding author. Fax: +1 6042913427.

E-mail address: saria@sfu.ca (S.M. van Anders).
}

proxies for prenatal hormones. Researchers have generally turned to measures that show early sex differences, following the logic that sexual differentiation is generally driven by prenatal sex steroids. Finger length ratio, a measure of the second finger to the fourth finger (2D:4D), shows a significant though small sex difference with males exhibiting a smaller average 2D:4D than females, and this is apparent in children as young as 2 years (Manning et al., 1998). These findings have led many to postulate a prenatal effect on digit ratios, likely from androgens as they differ between female and male fetuses (van de Beek et al., 2004).

In addition, the same Hox genes (specifically Hoxd and Hoxa) underlie the development of digits and genitals (Kondo et al., 1997) and their expression appears coordinated (Peichel et al., 1997). Given that genital masculinization is mediated by androgens (Nelson, 2000), and because digits and genitals develop in similar timeframes, it follows that digits likely develop at a time when androgens are in high circulation. If $2 \mathrm{D}: 4 \mathrm{D}$ is an accurate reflection of prenatal androgen exposure during its developmental period, this would prove extremely useful, providing a snapshot of a specific timeframe that ties hormones and development together. 
There are various lines of research that support the association between 2D:4D and prenatal androgens. These include research with clinical populations, such that females with congenital adrenal hyperplasia (in which prenatal androgens are elevated due to disrupted feedback) show lower 2D:4D than controls (Brown et al., 2002b; Ökten et al., 2002; cf. Buck et al., 2003), and amniocentesis relates low 2D:4D with a high ratio of free testosterone to free estradiol (Lutchmaya et al., 2004). Correlational research associates $2 \mathrm{D}: 4 \mathrm{D}$ with variables hypothesized by some to be related to high prenatal androgens (see Putz et al., 2004 for a review), including aggression (Bailey and Hurd, 2005; Benderlioglu and Nelson, 2004), athletic ability (Manning and Taylor, 2001), sexual orientation in women (Hall and Love, 2003; Rahman and Wilson, 2003; Williams et al., 2000; cf. Lippa, 2003; McFadden and Shubel, 2002) and maybe men (Lippa, 2003; Rahman and Wilson, 2003; cf. Williams et al., 2000), and gender role stereotypy (Brown et al., 2002a; Csathó et al., 2003). Though these studies provide converging evidence, data are correlational and open to interpretation, or use clinical populations and have limited generalizability.

One of the strongest 'experimental' human methods that addresses the effect of prenatal hormones, quasi-experimental though it is, takes advantage of the natural occurrence of dizygotic twin pairs who can be either same-sex (SS) or opposite-sex (OS). Androgens are much higher in male than female fetuses (van de Beek et al., 2004), and Miller (1994) proposed that hormones may be able to transfer between OS dizygotic twins during gestation. Uterine location in rodents has considerable influences on later behavior: female rats that gestated between two males are masculinized in various indices compared to females that gestated between two females (Clemens et al., 1978) due to testosterone transfer (Even et al., 1992). Therefore, it seems plausible that androgens can transfer from male to female fetuses.

A small number of studies have utilized the OS/SS twin paradigm to examine possible prenatal hormone contributions (reviewed in Cohen-Bendahan et al., 2005b). A few of these have found differences in the expected directions with spatial ability (Cole-Harding et al., 1988), cerebral lateralization (Cohen-Bendahan et al., 2004), subtypes of aggression (Cohen-Bendahan et al., 2005a), and sensationseeking (Resnick et al., 1993), though these are not markers and may have developmental influences beyond the prenatal period. Differences have also been found for tooth size (Dempsey et al., 1999) and otoacoustic emissions (faint noises emitted by the inner ear; McFadden, 1993; McFadden et al., 1996), but these are not well understood in behavioral terms.

2D:4D is an intriguing candidate for the OS/SS twin paradigm because of its relations with other variables. In addition, since it has been established that genitals and digits (but not yet ratios) are linked in development and occur when androgen levels are high, 2D:4D is a better candidate for a test of prenatal hormone-transfer theory than other variables. Here, we examine females and males from SS and OS twin pairs to test the possibility of prenatal androgen transfer and the likelihood of a prenatal foundation for 2D:4D. We hypothesized that OS females would exhibit lower (i.e. more male-typical) 2D:4D than SS females, reflecting higher prenatal androgen exposure for OS females. We included males for exploratory reasons, with a very tentative hypothesis for SS males to show lower (more male-typical) ratios than OS males possibly reflecting higher androgen exposure, because it is unclear from animal literature or theoretical considerations what effects higherthan-normal androgens in utero have on males, and whether androgen levels would be markedly higher for males gestating with other males.

\section{Methods}

\section{Participants}

Dizygotic twins were recruited from preexisting Canadian twin registries at the University of Western Ontario in London, Ontario, and the University of British Columbia in Vancouver, British Columbia, with zygosity predetermined using a questionnaire (Goldsmith, 1991). The participants were under 18, so legal guardians of participants were contacted about the present study. Participants had a mean age of 10.21 years; the youngest participants were 4 years, and the oldest were 15 years. There were 58 individuals in the study, but one set of OS twins sent in digital images of their hands that were of poor quality and may have had size distortions, and thus were not included. This left $16 \mathrm{SS}$ females, 9 OS females, 9 OS males, and 22 SS males, from 9 OS twin pairs, 8 SS female twin pairs, and 11 SS male twin pairs. For reasons of picture quality or lack of landmark location, measures could not be taken from one OS male (left hand) and one SS male (right hand).

\section{Materials and procedure}

In London, an experimenter visited the houses of participants with a portable photocopier/printer. Participants and their guardians were asked to sign informed consent forms, and then participants placed the palmar surface of each hand on the photocopier surface, with each hand photocopied in turn. In Vancouver, participants were mailed a package containing informed consent forms collecting signatures of participants and their guardians, instructions for making the photocopies, and addressed stamped envelopes for returning the consent forms and the photocopies.

Finger lengths were measured on transparencies placed on the photocopies by marking the most basal crease of the finger and the top of the finger on second and fourth digits of the left and right hands, a method that has been used 
successfully in many previous studies (Brown et al., 2002b; Coolican and Peters, 2003; Fink et al., 2004; Manning et al., 2004a,b; Putz et al., 2004; Rahman and Wilson, 2003; Roney and Maestripieri, 2004; van Anders and Hampson, 2005). We then used a transparent ruler to measure the finger lengths to the nearest $0.5 \mathrm{~mm}$. This method has been shown to have high reliability (van Anders and Hampson, 2005). We then divided the second by the fourth digit on the left hand to obtain L2D:4D, and on the right hand for R2D:4D.

\section{Results}

Analyses were conducted with the Statistical Package for the Social Sciences, v. 11.0.1. Independent $t$ tests were used to calculate group differences in 2D:4D. All analyses are two-tailed unless otherwise indicated as with a priori hypotheses, and one female was removed from the withinfemale analyses as her L2D:4D was nearly 3SD from the female mean. We note that 2D:4D measures were not significantly correlated between SS and OS pair members, indicating that the measures were not dependent in analyses.

As expected, males had significantly lower 2D:4D than females, though only on the left hand, L2D:4D $t(52)=2.45$, $P=0.009$ (one-tailed), R2D:4D $t(53)=0.13, P=0.448$ (one-tailed). As noted, previous research has shown significant associations with 2D:4D on both the right and the left hand only (Putz et al., 2004); Manning et al. (2004a,b) found only left hand differences.

There were no significant differences between SS and OS males (see Fig. 1) on the L2D:4D, $t(28)=-0.96, P=0.346$, or the R2D:4D, $t(28)=0.298, P=0.768$. As hypothesized, we found that 2D:4D was significantly lower in OS females than SS females (see Fig. 1) on the left hand, L2D:4D $t(22)=2.30, P=0.016$, one-tailed, though not on the right hand, R2D:4D $t(23)=-0.26, P=0.398$, one-tailed. The finding for the left hand only is consistent with our finding for the sex difference on the left hand only as well.

The pattern in females suggests a masculinization in OS females as opposed to a feminization in SS females, consistent with the notion of prenatal sexual differentiation driven by androgens released by males. 2D:4D in OS females did not differ significantly from OS males, L2D:4D, $t(15)=-0.12, P=0.908$, R2D:4D, $t(16)=$ $0.32, P=0.752$, but did differ significantly between SS females and SS males on the L2D:4D, $t(35)=2.86, P=$ 0.007 , though not on the R2D:4D, $t(35)=-0.14, P=$ 0.889 . And, OS females showed an average L2D:4D that was lower than the female average generally found in other published reports.

\section{Discussion}

We studied 2D:4D in females from same-sex (SS) and opposite-sex (OS) twin pairs to test prenatal hormonetransfer theory and to test for evidence of prenatal development of 2D:4D. Our results show masculinization in OS females relative to $\mathrm{SS}$ females. Based on these data, we suggest that prenatal androgens are high in OS males at the same time 2D:4D is developing in OS females, and exert a masculinizing effect on the female ratio via hormonetransfer. It is unlikely that growing up with a male co-twin would account for the differences in this physiological trait, as there is no evidence of postnatal effects on 2D:4D; the earliest age studied - 2 years - has shown the reliable sex difference (Manning et al., 1998) and evidence seems to show that OS females do not engage in more male-sex typed play (Henderson and Berenbaum, 1997). The effect size for the sex difference on the left hand in our data was 0.68 (Cohen's d), which is comparable to prior studies (e.g. 0.74: McFadden and Shubel, 2002); the twin effect was 0.87, which is comparable to relevant studies (e.g. 0.86: CohenBendahan et al., 2005a).

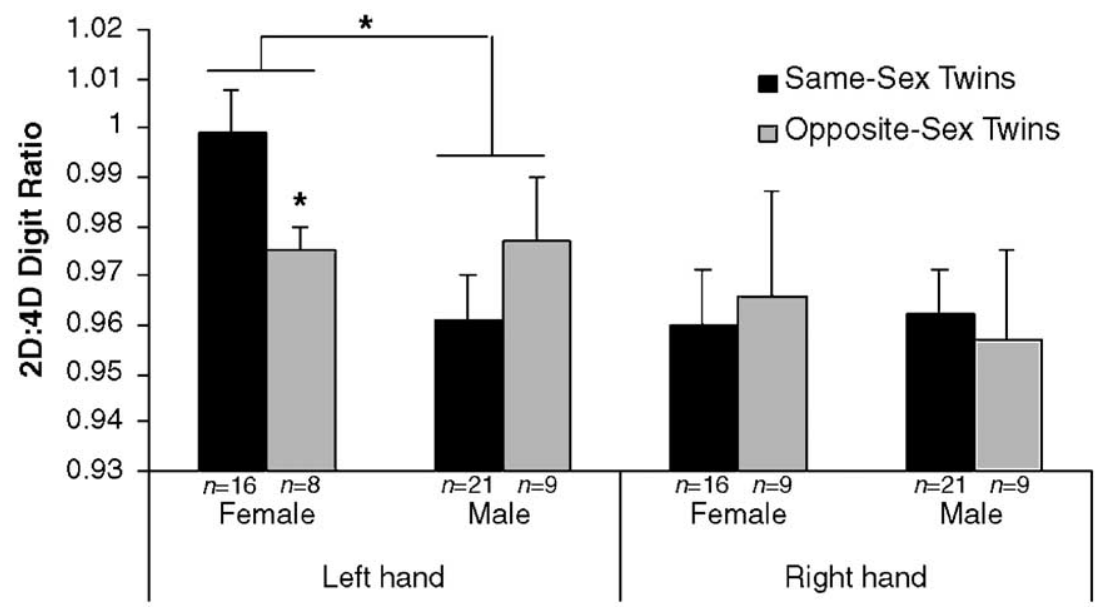

Fig. 1. Mean finger-length ratios (second digit:fourth digit) on the left and right hands in males and females from same-sex (SS) and opposite-sex (OS) twin pairs. * Indicates a significant difference between SS and OS females, and between males and females, at $\alpha<0.05$. 
One recent doctoral dissertation (Cohen-Bendahan, 2005) reported an unsuccessful attempt to find a difference between Dutch SS and OS females in 2D:4D, though the means were in the expected direction. We are unsure why our results differ, though Cohen-Bendahan's study did not replicate the established sex difference either. Ethnic differences have been shown to affect 2D:4D (Manning et al., 2004a,b) more strongly than sex, but it seems unlikely that this would account for the disparity. One major and interesting difference between our studies is that Cohen-Bendahan's male sample included only OS boys; though we found no significant difference between OS and SS boys, the means were in the expected direction ( $\mathrm{SS}<\mathrm{OS}$ ), and it is possible that such a difference would be significant with a larger sample size. If SS males do exhibit smaller ratios than OS boys, and OS females exhibit ratios that are near male-typical ratios, then the exclusion of SS males in a comparison by sex would be a key omission. One other potential limitation of our study is the finding of significance on the left hand digit ratio only. However, this is consistent throughout our results, which we argue attests to the integrity of our findings, but begs the question of why. As noted, the literature shows findings on the left hand, the right hand, or both hands with little apparent pattern (Putz et al., 2004). Obviously, further replication of our results is needed including SS and OS males and females.

We conclude by noting that the masculinized fingerlength ratios seen in OS females relative to SS females most likely are the result of prenatal hormone-transfer, such that androgens from male co-twins exert subtle but detectable developmental effects on their female co-twins. We suggest that the OS/SS twin paradigm is a strong and meaningful way to test experimental (or quasi-experimental) questions about prenatal hormone influences on development, behavior, and health. We also suggest that 2D:4D appears to provide a meaningful window into prenatal hormones and can be used with increased confidence as a marker of prenatal androgen exposure during genital differentiation specifically.

As noted in our Introduction, 2D:4D has been associated with such a wide array of variables, in what has appeared to be a somewhat atheoretical fashion to some. It may be that individuals with high androgens at genital differentiation and digit ratio development also exhibit high androgens throughout gestation, leading to measurable associations between 2D:4D and variables associated with androgen exposure during other times of fetal development.

We do not suggest that all variables associated with prenatal androgens ought to differ between OS and SS females. Instead, only those variables that have somatic or neural substrates that develop when genitals develop, i.e. when androgen levels from male co-twins are extremely high, might be reasonably expected to show evidence of hormonetransfer. Variables associated with higher cortical and/or later gestational development, i.e. when androgen levels from male co-twins are likely low and may be too low to significantly affect female co-twins, have little theoretical justification for inclusion in tests of hormone-transfer. Wallen (2005) notes that, in rhesus monkeys, androgen exposure early in gestation affects genitals while later exposure may affect behavioral patterns. This may explain why some of the previous studies utilizing the OS/SS twin paradigm have failed to find significant effects, and why spatial abilities do not appear to be related to 2D:4D (Austin et al., 2002; Coolican and Peters, 2003; McFadden and Shubel, 2003; van Anders and Hampson, 2005; cf. Csathó et al., 2003) though they have been associated with prenatal androgens: there may be a disconnection between the period of development underlying the variable of interest, $2 \mathrm{D}: 4 \mathrm{D}$, and the time of hormone-transfer. Of course, the challenge is that we still have little understanding of the developmental timepoints in humans for most neural or somatic substrates for most variables of interest to psychologists.

\section{Acknowledgments}

The authors would like to thank Sheri A. Berenbaum, Celina C.C. Cohen-Bendahan, T. Edward Reed, and Neil V. Watson for reading an earlier draft of this manuscript and providing helpful suggestions. A poster pertaining to this paper was presented at the 3rd International Behavioral Development Symposium (2005) in Minot, ND.

\section{References}

Austin, E.J., Manning, J.T., McInroy, K., Mathews, E., 2002. A preliminary investigation of the associations between personality, cognitive ability and digit ratio. Pers. Individ. Differ. 33, 1115-1124.

Bailey, A.A., Hurd, P.L., 2005. Finger-length ratio (2D:4D) correlates with physical aggression in men but not in women. Biol. Psychol. 68, $215-222$.

Benderlioglu, Z., Nelson, R.J., 2004. Digit length ratios predict reactive aggression in women, but not in men. Horm. Behav. 46, 558-564.

Breedlove, S.M., 1994. Sexual differentiation of the human nervous system. Annu. Rev. Psychol. 45, 389-418.

Brown, W.M., Finn, C.J., Cooke, B.M., Breedlove, S.M., 2002a. Differences in finger length ratios between self-identified "butch" and "femme" lesbians. Arch. Sex. Behav. 31, 123-127.

Brown, W.M., Hines, M., Fane, B.A., Breedlove, S.M., 2002b. Masculinized finger length patterns in human males and females with congenital adrenal hyperplasia. Horm. Behav. 42, 380-386.

Buck, J.J., Williams, R.M., Hughes, I.A., Acerini, C.L., 2003. In-utero androgen exposure and 2nd to 4th digit length ratio-Comparisons between healthy controls and females with classical congenital adrenal hyperplasia. Hum. Reprod. 18, 976-979.

Clemens, L.G., Gladue, B.A., Coniglio, L.P., 1978. Prenatal endogenous androgenic influences on masculine sexual behaviour and genital morphology in male and female rats. Horm. Behav. 10, 40-53.

Cohen-Bendahan, C.C.C., 2005. Biological roots of sex differences: a longitudinal twin study. Thesis, University Medical Center Utrecht.

Cohen-Bendahan, C.C.C., Buitelaar, J.K., van Goozen, S.H.M., CohenKettenis, P.T., 2004. Prenatal exposure to testosterone and functional cerebral lateralization: a study in same-sex and opposite-sex twin girls. Psychoneuroendocrinology 29, 911-916.

Cohen-Bendahan, C.C.C., Buitelaar, J.K., van Goozen, S.H.M., Orlebeke, 
J.F., Cohen-Kettenis, P.T., 2005a. Is there an effect of prenatal testosterone on aggression and other behavioral traits? A study comparing same-sex and opposite-sex twin girls. Horm. Behav. 47, $230-237$.

Cohen-Bendahan, C.C.C., van de Beek, C., Berenbaum, S.A., 2005b. Prenatal sex hormone effects on child and adult sex-typed behaviour: methods and findings. Neurosci. Biobehav. Rev. 29, 353-384

Cole-Harding, S., Morstad, A.L., Wilson, J.R., 1988. Spatial ability in members of opposite-sex twin pairs. Behav. Genet. 18, 710.

Coolican, J., Peters, M., 2003. Sexual dimorphism in the 2D/4D ratio and its relation to mental rotation performance. Evol. Hum. Behav. 24, $179-183$.

Csathó, Á., Osváth, A., Bicsák, É., Karádi, K., Manning, J., Kállai, J., 2003. Sex role identity related to the ratio of second to fourth digit length in women. Biol. Psychol. 62, 147-156.

Dempsey, P.J., Townsend, G.C., Richards, L.C., 1999. Increased tooth crown size in females with twin brothers: evidence for hormonal diffusion between human twins in utero. Am. J. Hum. Biol. 11, $577-586$.

Even, M.D., Dhar, M.G., vom Saal, F.S., 1992. Transport of steroids between fetuses via amniotic fluid in relation to the intrauterine position phenomenon in rats. J. Reprod. Fertil. 96, 709-716.

Fink, B., Manning, J.T., Neave, N., 2004. Second to fourth digit ratio and the 'big five' personality factors. Pers. Individ. Differ. 37, 495-503.

Goldsmith, H.H., 1991. A zygosity questionnaire for young twins: a research note. Behav. Genet. 21, 257-269.

Goy, R.W., Phoenix, C.H., 1972. The effects of testosterone proprionate administered before birth on the development of behaviour in genetic female rhesus monkeys. UCLA Forum Med. Sci. 15, 193-201.

Hall, L.S., Love, C.T., 2003. Finger-length ratios in female monozygotic twins discordant for sexual orientation. Arch. Sex. Behav. 32, 23-28.

Henderson, B.A., Berenbaum, S.A., 1997. Sex-typed play in opposite-sex twins. Dev. Psychobiol. 31, 115-123.

Kondo, T., Zákány, J., Innis, J.W., Duboule, D., 1997. Of fingers, toes and penises. Nature 390, 29.

Lippa, R.A., 2003. Are 2D:4D finger-length ratios related to sexual orientation? Yes for men, no for women. J. Pers. Soc. Psychol. 85, $179-188$.

Lutchmaya, S., Baron-Cohen, S., Raggatt, P., Knickmeyer, R., Manning, J.T., 2004. 2nd to 4th digit ratios, fetal testosterone and estradiol. Early Hum. Dev. 77, 23-28.

Manning, J.T., Taylor, R.P., 2001. 2nd to 4th digit ratio and male ability in sport: implications for sexual selection in humans. Evol. Hum. Behav. $22,61-69$.

Manning, J.T., Scutt, D., Wilson, J., Lewis-Jones, D.I., 1998. The ratio of 2nd to 4th digit length: a predictor of sperm numbers and concentrations of testosterone, luteinizing hormone and oestrogen. Hum. Reprod. 13, $3000-3004$.

Manning, J.T., Bundred, P.E., Mather, F.M., 2004a. Second to fourth digit ratio, sexual selection, and skin colour. Evol. Hum. Behav. 25, $38-50$.

Manning, J.T., Stewart, A., Bundred, P.E., Trivers, R.L., 2004b. Sex and ethnic differences in 2nd to 4th digit ratio of children. Early Hum. Dev. $80,161-168$

McFadden, D., 1993. A masculinizing effect on the auditory systems of human females having male co-twins. Proc. Natl. Acad. Sci. U. S. A. 90, 11900-11904.

McFadden, D., Shubel, E., 2002. Relative lengths of fingers and toes in human males and females. Horm. Behav. 42, 492-500.

McFadden, D., Shubel, E., 2003. The relationships between otoacoustic emissions and relative lengths of fingers and toes in humans. Horm. Behav. 43, 421-429.

McFadden, D., Loehlin, J.C., Pasanen, E.G., 1996. Additional findings on heritability and prenatal masculinization of cochlear mechanisms: clickevoked otoacoustic emissions. Hear. Res. 97, 102-119.

Miller, E.M., 1994. Prenatal sex hormone transfer: a reason to study opposite-sex twins. Pers. Individ. Differ. 17, 511-529.

Nagamani, M., McDonough, P.G., Ellegood, J.O., Mahesh, V.B., 1979. Maternal and amniotic fluid steroids throughout human pregnancy. Am. J. Obstet. Gynecol. 134, 674-680.

Nelson, R.J., 2000. An Introduction to Behavioral Endocrinology, 2nd ed. Sinauer Associates, Massachusetts.

Ökten, A., Kalyoncu, M., Yaris, N., 2002. The ratio of second- and fourthdigit lengths and congenital adrenal hyperplasia due to 21-hydroxylase deficiency. Early Hum. Dev. 70, 47-54.

Peichel, C.L., Prabhakaran, B., Vogt, T.F., 1997. The mouse Ulnaless mutation deregulates posters $\operatorname{HoxD}$ gene expression and alters appendicular patterning. Development 124, 3481-3492.

Putz, D.A., Gaulin, S.J.C., Sporter, R.J., McBurney, D.H., 2004. Sex hormones and finger length: what does 2D:4D indicate? Evol. Hum. Behav. 25, 182-199.

Rahman, Q., Wilson, G.D., 2003. Sexual orientation and the 2nd to 4th finger length ratio: evidence for organising effects of sex hormones or developmental instability? Psychoneuroendocrinology 28, 288-303.

Resnick, S.M., Gottesman, I.I., McGue, M., 1993. Sensation seeking in opposite-sex twins: an effect of prenatal hormones? Behav. Genet. 23 (4), 323-329.

Roney, J.R., Maestripieri, D., 2004. Relative digit lengths predict men's behaviour and attractiveness during social interactions with women. Hum. Nat. 15, 271-282.

van Anders, S.M., Hampson, E., 2005. Testing the prenatal androgen hypothesis: measuring digit ratios, sexual orientation, and spatial abilities in adults. Horm. Behav. 47, 92-98.

van de Beek, C., Thijssen, J.H., Cohen-Kettenis, P.T., van Goozen, S.H., Buitelaar, J.K., 2004. Relationships between sex hormones assessed in amniotic fluid, and maternal and umbilical cord serum: what is the best source of information to investigate the effects of fetal hormone exposure? Horm. Behav. 46, 663-669.

Wallen, K., 2005. Hormonal influences on sexually differentiated behaviour in nonhuman primates. Front. Neuroendocrinol. 26, 7-26.

Williams, R.J., Pepitone, M.E., Chistensen, S.E., Cooke, B.M., Huberman, A.D., Breedlove, N.J., Breedlove, R.J., Jordan, C.L., Breedlove, S.M., 2000. Finger-length ratios and sexual orientation. Nature 404, $455-456$ 